www.candrive.ca/En/About/what_candrive.asp), to weigh the legal and ethical responsibilities in this difficult area, and to broach the topic of driving retirement and move toward a workable plan. The Hartford Insurance Corporation, for example, offers 2 free publications that make excellent patient handouts: At the crossroads: a guide to Alzheimer's disease, dementia and driving (available at www.thehartford.com (alzheimers) and We need to talk: family conversations with older drivers (www.thehartford.com/talkwitholderdrivers). Community organizations, such as the Alzheimer's Association, also can assist with driving retirement issues. Individualized transportation options are needed for older adults with dementia who do not have an informal network of family or social contacts that can fulfill this role. Meanwhile, physicians should know the laws and reporting requirements for unsafe drivers in their province or state, and work proactively with patients and their families to achieve driving retirement before serious problems occur.

This article has been peer reviewed.

From the Divisions of Geriatrics (Carr) and Neurology (Meuser, Morris), Department of Medicine and the Alzheimer's Disease Research Center, Washington University in St. Louis School of Medicine, St. Louis, Mo.

Competing interests: David Carr is a consultant for the American Medical Association. John Morris has been involved in clinical trials of antidementia drugs sponsored by Elan and by Eli Lilly and Company, and has accepted consultancy fees or speaking honoraria from Amgen, AstraZeneca, Axonyx, Elan, Genworth, Myriad, Novartis and Sanofi-Aventis.
Contributors: This article was written and revised as a cooperative effort by all authors, all of whom approved the version to be published.

Acknowledgements: This commentary was supported by National Institute on Aging (Bethesda, Md.) grants P50 AG0568I and Por AG0339I.

\section{REFERENCES}

I. Fain M. Should older drivers have to prove that they are able to drive? Arch Intern Med 2003; 163:2126-8.

2. Meuser T, Carr DB, Berg-Weger M, et al. Driving and dementia in older adults implementation and evaluation of a continuing education project. Gerontologist 2006;46(5). In press.

3. Perkinson MA, Berg-Weger ML, Carr DB, et al. Driving and dementia of the Alzheimer type: beliefs and cessation strategies among stakeholders. Gerontologist 2005; $45: 676-85$.

4. Herrmann N, Rapoport MJ, Sambrook R, et al. Predictors of driving cessation in mild to moderate dementia. CMAJ 2006;I75(6):59I-5.

5. Sambrook R, Herrmann N, Hebert R, et al. Canadian Outcomes Study in Dementia: study methods and patient characteristics. Can J Psychiatry 2004;49:417-27.

6. Gilhotra JS, Mitchell P, Ivers R, et al. Impaired vision and other factors associated with driving cessation in the elderly: the Blue Mountains Eye Studyx. Clin Experiment Ophthalmol 200I;29:104-7.

7. Carr DB, Shead V, Storandt M. Driving cessation in older adults with DAT. Gerontologist 2005; $45: 824-7$.

8. Hakamies-Blomqvist L, Siren A. Deconstructing a gender difference: driving cessation and personal driving history of older women. J Safety Res 2003;34:383-8.

9. Trobe JD, Waller PF, Cook-Flanagan CA, et al. Crashes and violations among drivers with Alzheimer disease. Arch Neurol I996;53:4II-6.

Io. Staplin L, Hunt L. Driver programs: transportation in an aging society. Washington: Transportation Research Board; 2004. p. 69-94.

Correspondence to: Dr. John C. Morris, Alzheimer Disease Research Center, 4488 Forest Park Avenue, Suite I6o, St. Louis MO 63108; fax 314 286-2763; morrisj@abraxas.wustl.edu

\title{
Understanding the health of Indigenous peoples in Canada: key methodological and conceptual challenges
}

\section{Janet Smylie, Marcia Anderson}

$\mathrm{O}$ ver the past year I have had the privilege of working with Métis elder and author Maria Campbell and 2 northern Saskatchewan communities on an oral history project. The project, "Kokum, what makes a baby well?" is designed to archive historic understandings of infant wellness and see if there are concepts that can be meaningfully applied to the measurement of infant health today.

Several months ago, we were working through the Cree translation of the project consent forms. As we came to the term "health measurement," Maria knitted her brow and told of me, "There is no word in Cree for this. There is a word for . 'measurement,' but we use it to talk about the amount of wood cut or the size of a catch of fish."

For more than a decade, health researchers have systematically documented inequities in health status between Aboriginal and non-Aboriginal Canadians. ${ }^{1-3}$ In this article, we highlight several key challenges that affect the collection, in- terpretation, and application of Aboriginal health assessment data in Canada. These include data coverage and quality; data jurisdiction and utility; data governance and relevance; and infrastructure and human resource capacity.

\section{Data coverage and quality}

Monitoring health status to "identify and solve community health problems" tops the American Public Health Association's list of essential services. ${ }^{4}$ Health assessment data are drawn from 5 principal sources: census, vital registration, health surveys, health services utilization data and surveillance systems. A basic epidemiologic tenet is that, when populationbased rates are calculated from these data sources, enumeration of the population of interest should be as complete as possible; and the count of the event of interest in that population, as accurate as possible. Rates based on incomplete enu- 
merations have problems of coverage; those based on faulty data or calculation methods, problems of quality. Users of data on Aboriginal health status in Canada immediately encounter important issues of both coverage and quality for all 5 principal data sources (Box I). ${ }^{5}$

The major coverage challenge is a lack of accurate identification that respectfully, systematically, comprehensively and consistently recognizes self-identified First Nations, Métis or Inuit ethnicity. The number of people self-reporting Aboriginal ancestry in the 200I census was just over I. 3 million, or $4.4 \%$ of the Canadian population. ${ }^{6}$ Of those self-identified as being Aboriginal, around $62 \%$ identified themselves as "North American Indian"; $30 \%$, as Métis; and 5\%, as Inuit. ${ }^{6}$ The coverage of noncensus-derived Aboriginal health data ranges from o to over $90 \%$, depending on the region and the data source. The national census and the Aboriginal Peoples Survey are the only major data sources that permit participants to identify themselves as Métis. Consequently, coverage is rarely better than $66 \%$. When data are restricted to First Nations people living on a reserve (e.g., the First Nations Regional Health Survey and the postal code-based CIHI data), coverage falls to less than $33 \%$.

Quality challenges principally spring from the use of substandard data sources, substandard methods or both. For example, in May 2005, the First Nations and Inuit Health Branch (FNIHB) of Health Canada released an infant mortality rate ${ }^{7}$ for First Nations persons living on a reserve of 6.4 per 1000. This rate was based on vital registration data (of variable quality) for the 4 Western provinces combined with data collected from nursing stations for the rest of the country (i.e., where vital registration data were unavailable). The FNIHB rate differs from regional rates that have met the scrutiny of peer review, and is considered an underestimate because the methods used were biased toward an undercounting of infant deaths relative to births.

The impact of poor assessment data on health planning and evaluation is further exemplified by the Aboriginal health targets announced by former Prime Minister Paul Martin at the Kelowna Accord meeting in November 2005: \$1.315 billion was pledged to reduce infant mortality, youth suicide, childhood obesity and diabetes by $20 \%$ in 5 years and by $50 \%$ in Io years, and to double the number of Aboriginal health professionals by 2016. These targets resulted from more than 2 years of planning and negotiation by federal, provincial, territorial and national Aboriginal governing bodies. Strikingly absent from the Kelowna discussions was acknowledgement that accurate baseline data do not exist for any of the identified targets. The generalized nature of the reduction targets and lack of feasibility are causes of further concern. Not only is a reduction of $50 \%$ in the rate of death of infants a very different endeavour than a $50 \%$ reduction in youth suicide, it in fact sets a target for infant mortality lower than any in the industrialized world.

\section{Data jurisdiction and utility}

Although national-level Aboriginal data are useful to measure health disparities between the Aboriginal and non-Aboriginal people of Canada, they are inadequate for the planning and delivery of public health services.
Box 1: Canadian sources of data for Aboriginal health assessment and associated (bulleted) quality concerns

\section{Census data}

Data produced when participants identify themselves as First Nations (registered and nonregistered), Métis or Inuit

- Nonparticipation is common

- On many reserves, enumeration is incomplete

- Mobility and overrepresentation of homeless people contributes to undercounting of Aboriginal groups

- The ethnicity question appears on only about $20 \%$ of forms

- Aboriginal people may choose not to self-identify to government employees

- Ethnic mobility contributes to inaccuracy of data

Vital registration data

INAC's Indian Register: First Nations-specific rates generated from cross-linkage of data from 4 provinces

- Lack of prospectively collected data on ethnicity by voluntary self-identification excludes generation of rates for nonregistered First Nations, Métis and Inuit people

Questions about Aboriginal ethnicity on the registration forms of some provinces and territories

- Privacy concerns about transfer of the INAC registry

- Lack of standardization of ethnicity questions on forms

Data from health surveys

National health surveys (none to very limited)

- Most national surveys done by Statistics Canada exclude sampling from reserves, don't ask about Aboriginal ethnicity, or use a sample too small to generate anything other than national pan-Aboriginal data

Aboriginal Peoples Survey: nonregistered First Nations, Métis and Inuit people

- Sampling frames are derived from the census data from self-identified Aboriginal people, so coverage issues are the same as for the census

- Done only every 10 years

First Nations Regional Health Survey: registered First Nations people on Reserves

- Excludes large segments of the Aboriginal population

- Content is not entirely comparable to the national survey

Health services utilization data

Compiled by Canadian Institute of Health Information $(\mathrm{CIHI})^{*}$

- Compiled by geographic region: no ethnic-specific data

- In some regions where the proportion of Aboriginal people is very high (e.g., Northern Saskatchewan and Nunavut), geography can serve as proxy measure

\section{Data from surveillance systems}

Registered First Nations people only, by data linkage in National Diabetes Surveillance System and some surveillance systems for notifiable diseases

- Lack of standardized, inclusive means to permit selfidentification of Aboriginal ethnicity

Note: INAC = Indian and Northern Affairs Canada.

*Reports have been published in which provincial health systems linked their databases with the Indian Register or Band Membership lists to generate health-service utilization data specific to Aboriginal people. 
Aboriginal populations in Canada are diverse and multijurisdictional. About half of Aboriginal people in Canada now live in urban areas. Not only does the setup of health systems vary greatly according to Aboriginal ethnicity (First Nations people with or without registered treaty status, Inuit and Métis) and geography (remote, rural, on-reserve, urban), so does provider jurisdiction (federal, provincial/territorial, Aboriginal governing authority or a combination thereof). As well as thwarting access to comprehensive health care, these multiple jurisdictions foil the collection of comprehensive and reliable health-assessment data.

\section{Currently, only io-2o people of Indigenous an- cestry have graduate-level training in public health.}

A recent review ${ }^{8}$ of systems Indigenous health measurement systems in Canada, Australia and New Zealand identified a relative underdevelopment of community-level systems and hence a deficiency in the support of local service development. Appropriate public-health planning and response requires health-assessment information that accurately reflects Aboriginal ethnicity and geographic location while effectively negotiating jurisdictional complexities. These data need to be readily available to First Nations, Métis and Inuit health planners and policy makers at the local, regional and national levels.

\section{Data governance and relevance}

For centuries, Indigenous peoples across the globe have been calling for recognition of their fundamental right to ancestral homelands and self-government. Over the past decade, First Nations, Métis and Inuit governing authorities in Canada have increasingly advocated for the recognition that the right to self-government includes the right to selfgovernance of population-based information, including health information. For example, the First Nations Regional Longitudinal Health Survey recently conducted by the First Nations Centre at the National Aboriginal Health Organization $^{9}$ carefully addressed issues of data ownership, control, access and possession (OCAP) by participant First Nations communities. Indigenous scholars reiterate that Indigenous rights include the right to "construct knowledge in accordance with self-determined definitions of what is real and what is valuable." 10

Although Indigenous models of health are diverse, they generally differ from non-Indigenous biomedical models in that they consider the health of the whole community and its surrounding environment. Several Aboriginal groups in Canada have responded to the conceptual gap between
Indigenous and more universally accepted health measures by initiating their own health measurement models. The initiatives that we have been able to identify are in the early stages of development, apply culturally specific conceptualizations of health, require Indigenous leadership, and tend to emphasize local social determinants, upstream measures, collective measures and wellness. ${ }^{5}$ For example, 9 First Nations communities in northern Saskatchewan have been working in partnership with Drs. Sylvia Abonyi and Bonnie Jeffery to develop a set of indicators to plan, track and evaluate community-based health programs. These indicators are drawn from the domains of economic viability, environment, identity and culture, healthy lifestyle, food security, and community services and infrastructure. The resulting community health toolkit has been piloted in one community to track progress in each domain and was found to be of value by local health directors. ${ }^{11,12}$ In 2002, the Inuit Tapairiit Kanatami, the national Inuit governing organization, released the Inuksiutiin Health Information Framework. This document outlines the process components that would be required to develop health data that are relevant and useful to the Inuit population in Canada; the framework was premised on Inuit leadership as well as Inuuqatigiittiarniq - the holistic worldview of Inuit health. ${ }^{13}$

The use of Indigenous ways of knowing and understanding health and healing can enrich health-assessment data sets and improve their relevance and usefulness for communitylevel planning and evaluation. Such locally customized, culturally relevant measures are in the early stage of development. Although it is logical to assume that increased relevance and uptake at the community level will result in improved health tracking and ultimately improved health outcomes, we have not yet found any published examples. The support of First Nations, Inuit and Métis communities in the further development and evaluation of culturally relevant, community-level health-tracking systems is an important health-assessment priority.

\section{Infrastructure and human resource capacity}

There are major gaps in health information systems for Canada's Aboriginal peoples, with respect to universally accepted measures and measurement sources as well as in the development of culturally specific and locally relevant indicators. Access to health assessment data at the community or multicommunity level is particularly problematic. Issues of jurisdiction and Aboriginal self-determination will require the development of collaborative partnerships between First Nations, Métis and Inuit governing authorities and health information agencies.

There is much infrastructure to be developed, which will require a workforce that is competently able to draw on Aboriginal conceptual and governance frameworks as well as the best public-health tools that the West has to offer. Canada is behind Australia, New Zealand and the United States in the systematic development of an Aboriginal public-health workforce. For example, currently we are able to identify only between Io and 20 people of Indigenous ancestry with graduatelevel training in public health. 


\section{Concluding remarks}

Several key methodological and conceptual challenges affect the collection, analysis and use of data for Aboriginal health assessment in Canada. Indigenous health enumeration and inequities in health status are international concerns. Canada can benefit from collaboration with other countries that face similar challenges in the health assessment of Indigenous peoples. Internationally, many Indigenous communities are becoming full partners in the generation of knowledge unique to their ancestral claims and inheritance. International partnerships offer opportunities to learn about other Indigenous communities and borrow from their datacollection systems. For example, in Australia and New Zealand the national health ministries require the collection of (self-identified) ethnicity data whenever use is made of the health care system, with progress toward the implemention of this policy in all health sectors. ${ }^{14,15}$ Both countries record self-reported Indigenous ethnicity data on birth and death certificates.

We need to acknowledge these transformative times and participate fully with Indigenous peoples to develop systems to collect data that are relevant and culturally meaningful. Although the health care system in Canada is touted by many as one of the best in the world, considerable changes are required for Indigenous peoples to realize their inherent right to good health. Accurate and culturally meaningful health assessment is one step toward this goal.

The challenges of community relevance, infrastructure and capacity will be particularly important as we progress toward state-of-the-art Indigenous health assessment in Canada. First Nations, Inuit and Métis makers and managers of health policy need comprehensive and reliable health-assessment measures that reflect the needs, priorities and understandings of health in their local and regional jurisdictions. These measures should include locally relevant and customized First Nations, Métis and Inuit indicators as well as universally recognized public-health indicators.

This article has been peer reviewed.

Janet Smylie is with the Department of Community Health and Epidemiology, University of Saskatchewan, and the Indigenous Peoples Health Research Centre, Saskatoon, Sask. Marcia Anderson is with the Department of Internal Medicine, College of Medicine, University of Saskatchewan, and the Johns Hopkins Bloomberg School of Public Health, Baltimore, Md.

Competing interests: None declared.

Contributors: This paper draws on original research conducted by Janet Smylie and Marcia Anderson. Janet Smylie drafted the paper, with substantive input from Marcia Anderson. Both authors made critical revisions to the article and approved the version to be published.
Acknowledgements: We greatly appreciate the input of Dr. Barry Lavallee on the initial outline of this paper.

This research was supported by operating grants from the Canadian Institutes of Health Research (CIHR) and the Saskatchewan Health Research Foundation. Dr. Smylie is supported by a CIHR-Associated Medical Services Inc.-Institute of Aboriginal Peoples' Health Phase Two Senior Research Fellowship in the History of Aboriginal Health and Medicine.

\section{REFERENCES}

I. MacMillan HL, MacMillan AB, Offord DR, et al. Aboriginal health [review]. CMA I996;I55(II):1569-78.

2. Smylie J; Aboriginal Health Issues Committee. A guide for health professionals working with aboriginal peoples: cross cultural understanding. J SOGC 2001;23: 54-68. As SOGC Policy Statement No. Ioo, it is also available at www.sogc.org /guidelines/public/IooE-PS4-February200I.pdf (accessed 2006 Aug I5).

3. Health Council of Canada. The health status of Canada's First Nations, Metis, and Inuit people - a background paper to accompany "Health Care Renewal in Canada: Accelerating Change.” Ottawa: The Council; 2005. Available: http://healthcouncilcanada .ca/docs/papers/2005/BkgrdHealthyCdnsENG.pdf (accessed 2005 Sept. 30).

4. Harrell JA, Baker EL; American Public Health Association. The essential services of public health. Available: www.apha.org/ppp/science/roES.htm (accessed 2006 Aug 14).

5. Anderson M, Smylie J, Anderson I, et al. First Nations, Métis, and Inuit Health Indicators in Canada. A background paper for the project "Action oriented indicators of health and health systems development for Indigenous peoples in Canada, Australia, and New Zealand." Saskatoon: Indigeous Peoples' Health Research Centre; 2006. Available: www.iphrc.ca/text/canadian.pdf (accessed 2006 Aug I4).

6. Statistics Canada. 20or census: analysis series. Aboriginal peoples of Canada: a demographic profile. Ottawa: Ministry of Industry; 2003. Available: www 2.statcan .ca/english/censusor/products/analytic/companion/abor/pdf/96Foo30XIE200I007 .pdf (accessed 2006 Aug I4).

7. First Nations and Inuit Health Branch. FNIHB fact sheet. Ottawa: Health Information and Analysis Division, FNIBH; 2005.

8. Smylie JK, Anderson I, Ratima M, et al. Indigenous health performance measurement systems in Canada, Australia, and New Zealand. Lancet 2006;367:2029-31.

9. First Nations Centre. National Aboriginal Health Organization. First nations regional longitudinal health survey (RHS) 2002/03: results for adults, youth and children living in First Nations communities. Ottawa: The Centre; 2005. Available: www.naho.ca/firstnations/english/documents/RHS2002-03TechnicalReport_oor .pdf (accessed 2006 Aug I4).

Io. Brant Castellano M. Ethics of aboriginal research. J Aboriginal Health 2004;I:98-II4. Available: www.naho.ca/english/pdf/journal_p98-II4.pdf (accessed 2006 Aug I4).

II. Abonyi S., Jeffery B. Developing a community health tool kit with Indigenous health organizations: moving population and public health knowledge into action. Ottawa: Canadian Institutes of Health Research; 2006. Available: www.cihr-irsc.gc .ca/e/30740.html (accessed 2006 Aug I4).

I2. Abonyi S, Jeffery B, Hamilton C. Development of an evaluative framework for use by first nations health organizations. 6th International Conference on the Scientific Basis of Health Services; 2005 Sep I8-20, 2005; Montreal, QC.

I3. Boyd \& Associates. Inuksiutiin Health Information Framework. Ottawa: Inuit Tapiriit Kanatami; 2002.

I4. Ratima M, Edwards W, Crengle S, et al. Maori health indicators: a background paper for the project "Action oriented indicators of health and health systems development for Indigenous peoples in Canada, Australia, and New Zealand." Saskatoon: Indigenous Peoples' Health Research Centre; 2006. Available: www.iphrc.ca /text/maori.pdf (accessed 2006 Aug I4).

I5. Anderson M, Anderson I, Smylie J, et al. Measuring the health of aboriginal and Torres Straight Islander peoples: a background paper for the project "Action oriented indicators of health and health systems development for Indigenous peoples in Canada, Australia, and New Zealand.” Saskatoon: Indigenous Peoples' Health Research Centre; 2006. Available: www.iphrc.ca/text/australian.pdf (accessed 2006 Aug I4).

Correspondence to: Dr. Janet Smylie, Department of Community Health and Epidemiology, University of Saskatchewan, Royal University Hospital Rm. 2762.1, 103 Hospital Drive, Saskatoon SK S7N oW8; fax 306 966-7920; jk.smylie@usask.ca 